\title{
The perceived and observed needs of patients with dementia admitted to acute medical wards
}

\begin{abstract}
It is acknowledged that the needs of persons living with dementia admitted in acute hospitals are not always met. Previous studies have focused on the perceived needs of professional caregivers or family members whilst the voices of patients with dementia in acute hospitals has not been extensively reported. This may have contributed to the under-recognition of the needs of persons living with dementia. The aim of this study was to categorize the perceived and observed needs of persons with dementia admitted in acute medical wards and to explore whether these needs are being or have been met. Thirteen people with dementia in three medical wards who could verbally communicate with the researcher, were purposively selected as research participants. Semi-structured interviews were conducted to elicit each participant's experiences of their hospital stay and whether their needs were perceived to have been/are being met. Moreover, routine care with the same participants was observed using Dementia Care Mapping. Maslow's Hierarchy of Needs, was used as a framework to categorize care needs. Our findings demonstrate that basic needs such as toileting, feeding, drinking, continence and comfort were not always met. Moreover, the largest gap between met and unmet needs was found in patients who were either under constant observation or unable to communicate. Too much emphasis was perceived and observed to be given on what staff considered as safety needs at the expense of other needs. The patients' need for social contact and self-esteem such as dignity and respect were often ignored and this led to patients feeling devalued. Hospital staff have to be more aware of the holistic needs of patients with dementia in acute settings and the way care is delivered in order to make up for these unmet needs thus facilitating person-centred care.
\end{abstract}

Keywords: dementia, acute hospitals, Maslow's Hierarchy of needs, patient perceptions, constant observation, qualitative research

Scerri A, Scerri C \& Innes A, The perceived and observed needs of patients with dementia admitted to acute medical wards, Dementia, 19 (6), pp. 1997-2017. Copyright (C) The Authors 2019. Reprinted by permission of SAGE Publications.

DOI: https://doi.org/10.1177/1471301218814383 


\section{Background}

According to the World Alzheimer Report (Prince et al., 2015), 46.8 million people worldwide were living with dementia in 2015 . This figure will most likely to double every 20 years, reaching 74.7 million in 2030 and 131.5 million in 2050. Similarly, the number of persons with dementia in Malta over 60 years in 2030 is projected to be close to 10,000 persons or $2.3 \%$ of the total Maltese population (Scerri \& Scerri, 2012). As a result of the global increase in dementia, the World Health Organisation (2012) acknowledged that dementia is 'a public health priority' with a need of increasing awareness in the hope of improving the treatment and care of these individuals.

Due to the varying co-morbid conditions, persons with dementia may be referred and admitted to an acute hospital. At any time, a quarter of the patients in an acute hospital are persons with dementia or cognitive impairment (Lakey, 2009; Royal College of Psychiatrists, 2011). Moreover, patients with dementia may account to as much as $42 \%$ of patients aged over 70 years in acute hospitals (Lyketsos et al., 2000; Sampson, Blanchard, Jones, Tookman \& King, 2009), whilst it is estimated that at least one quarter of hospital beds in United Kingdom are used by persons with dementia (Boaden, 2016).

There is evidence that the quality of care of patients with dementia in hospital settings is far from optimal (Dewing \& Dijk, 2016; Zekry et al., 2008) and can be very challenging (Clissett, Davina, Rowan, \& John, 2013). The Royal College of Psychiatrists (2011, 2013) carried out two national audits of dementia care in general hospitals in England and Wales and identified 'disappointing results' in the first Audit (2011). The second National Audit found that positive initiatives had been taken, namely; the development of Dementia Champions; compiling a life history (personal information) about persons with dementia when in hospital; and the reduction in the use of anti-psychotic medications. Nevertheless, a number of negative findings were also 
reported including a dearth of proper assessment for delirium risk and cognitive function and a general lack of staff awareness of how best to care for these patients, indicating a huge need for better staff training and support. Similarly, an audit in Northern Ireland found sup-optimal hospital care such as inadequate assessment, access to specialist services, staffing levels, staff training and discharge planning (Timmons et al., 2016). The UK Alzheimer Society (2016) reported that according to family perceptions, $60 \%$ of people with dementia were not being treated with dignity and understanding while in hospital, whilst more than $90 \%$ of those surveyed said that the hospital environment was frightening for these patients and made them more confused leading to delayed hospital discharges or falls. This has led the UK Alzheimer Society (2016) to develop recommendations to 'fix' dementia care in hospitals, based on the findings of these audits and following consultation with family members of persons with dementia.

In view of the increased interest, a number of studies have been published that sought to describe the experiences of people with dementia and cognitive impairment from different perspectives. Digby, Lee \& Williams (2016) carried out an integrative review to appraise research that explored how acute hospital care was viewed by persons with dementia and nurses. The authors concluded that caring for persons with dementia in acute care was perceived by ward staff as a low priority mainly as a result of the inability to adjust to needs of this client group. However, out of 24 studies reviewed, only 8 reported the perspectives of persons with dementia whilst some of these studies did not formally interview patients and used opportunistic conversations during periods of observation.

Most of the studies on hospital experiences focus on the perceived needs of professional caregivers or family members whilst the voices of patients with dementia in acute hospitals has not been extensively reported (Digby, Lee, \& Williams, 2016; Norman, 2006). This may have 
contributed to the under-recognition of the needs of persons with dementia. Besides, Prato et al. (2018) found that there was a divergence between the perspectives of staff members, patients and family members. Therefore, studies focusing more on exploring the views of persons with dementia and cognitive impairment in acute hospitals are needed (Bridges, Flatley, \& Meyer, 2010). Edvardsson and Nordvall (2006) concluded that experiences of care narrated by persons with dementia, present meaningful and useful information about their needs that should inform care practice.

\section{Methods}

Aim of the study

Using Maslow's levels of needs as an a priori framework, the aim of this study was to categorize the perceived and observed needs of persons with dementia in acute medical wards and to explore whether these needs are being or have been met.

\section{Research design}

Thirteen persons with dementia who were in-patients in three acute medical wards in a Maltese general hospital and who could participate in verbal conversations were asked about the experiences of their hospital stay. Persons with dementia who were too unwell were excluded. However, persons with dementia with evidence of 'challenging behaviour' were included. Recruitment was sought following discussion with the charge nurse of each ward who went through the patients' list during the time of data collection and identified patients with a known history of chronic cognitive impairment and dementia who met the inclusion criteria.

Participants were purposively selected from three 24-bedded acute medical wards out of a total of nine medical wards in a recently built acute hospital in Malta. The wards selected were a 
male ward and two female wards; one of which was being used as a transition ward for patients awaiting discharge to long-term care. The decision to restrict selection from medical wards only, was taken in view of the fact that patient turnover in these wards is generally lower than in other surgical and critical care wards so that it was possible that patients would have been staying in hospital for quite some time. All the wards had a similar layout except for the transitional ward that had a communal area where patients could sit around a large table in the middle of the ward.

A semi-structured interview schedule (Table 1) was developed with a set of questions that sought the views of these patients about their hospital stay. A number of introductory questions were used to open up discussion and to start to build a rapport with the patient. Pictures relevant to the questions were shown to the participants to aide discussions and conversation. Communication skills like prompting, paraphrasing and summarising were used to elicit further conversation between the researcher and the participant. When family members or formal ward staffs were present next to the patients, their views were also sought. Although the questions assisted the researchers in discussing the themes as described in Table 1, persons with dementia were given the opportunity and the time to elaborate further on topics that they found important. With the consent of each participant the interviews were audio-taped and transcribed verbatim.

Following the interviews, the same patients were observed for nine hours using Dementia Care Mapping (DCM) [Braford Dementia Group, 2005]. The field notes obtained using DCM were collected to complement the findings of the participants' responses. Initially, the field notes were categorised according to whether they were personal detractions (PD) - consisting of events when patients were observed to be put down and therefore their needs remained unmet 
and personal enhancers (PE)- consisting of events when the patient's wellbeing was sustained and their needs were met.

The transcripts and field notes were read by all researchers and the picture that began to emerge bore a striking resemblance to Maslow's categorisation of needs; physiological, safety, belongingness, esteem and 'being' needs. As a result, at data analysis stage this framework for organising the data obtained from the transcripts and field notes was selected to determine to what extent the perceived and observed hospital experiences, categorised according the Maslow's hierarchy needs, were being met or remained unmet.

\section{Theoretical Framework}

Maslow's Hierarchy of Needs Theory (Maslow, 1943), was one of the first frameworks for understanding how individuals' assessment of quality of life could be related to how well their needs were being met. According to Maslow, human needs can be categorised into five levels. Physiological needs such as food, water, heat and sleep are the most basic needs followed by 'safety' needs. These include the need to feel secure from harm or injury but also the freedom to do things on your own as long as you can (Maslow, 1943). The third set of needs consist of love, affection and belonging needs, followed by esteem needs - the human desire for selfrespect, esteem, independence and achievement. Unlike the previous four needs that have been referred to as the 'deficit' needs, the final need, self-actualisation, is known as the 'being' needs or the desire to fulfil ones' potential. Later, a sixth need was proposed by Maslow and referred to as 'self-transcendence' or the need to understand oneself through spiritual contemplation (Koltko-Rivera, 2006) [Figure 1].

One of the strongest criticisms of this theory is whether human needs are hierarchical (Wahba \& Bridwell, 1976) when they could be simultaneous and complementary (Max-Neef, 1991). 
Nevertheless, Maslow' theory of needs has been used to understand the needs of older persons in emergency departments (Nydén, Petersson, \& Nyström, 2003) and persons with dementia living in the community (Schölzel-Dorenbos, Meeuwsen, \& Rikkert, 2010). Based on Maslow Hierarchy of Needs, Schölzel-Dorenbos et al. (2010) developed the Hierarchy Model of Needs in Dementia and discussed how this model is associated with the health-related quality of life of persons with dementia living in the community. No study has yet discussed the needs of persons with dementia admitted in acute hospital settings using Maslow's six levels of needs as a theoretical framework.

\section{Ethical considerations}

An information sheet was provided to potential participants to enable them to give informed consent prior to their agreement to participate in the study. On consenting, participants were asked to sign a declaration. Ethical approval was obtained from the University Research Ethics Committee (UREC) of the University of Malta. Permission was also given from the administration of the participating hospital, the charge nurses of the three wards and from the consultants responsible for the patients.

It is acknowledged that some patients may not have fully comprehended the consent they were giving so, to minimize the risk of harm, process consent procedures (Dewing 2008), were followed by remaining vigilant to verbal or non-verbal signs that they did not wish to continue. Written consent from the patient or a proxy consent from their relatives, when patients could not sign their own consent, was given for tape-recorded interviews. All data were anonymized and stored securely to protect confidentiality. Pseudonyms were used when referring to the patients and their family members to maintain their anonymity. 


\section{Data analysis}

Under the theme 'biological and physiological needs', conversations and observations related to maintaining personal hygiene, toileting, feeding, drinking, pain, comfort, mobility and sleep were included. The 'safety needs' theme included abstracts of transcripts and observations related to issues that can influence patient safety in hospital (e.g. wandering and the risk falls) and the presence of a safe environment that enables them to do things on their own. Conversations and observations when patients received or missed any signs of love, attention and affection from the ward staff, relatives or other patients were categorised under the 'belongingness needs' theme. 'Self-esteem needs' included abstracts of conversations or observations when the patient's dignity, respect, independency and privacy were either preserved or lost. Conversations/observations when patients were empowered/disempowered in being meaningful or useful and involved in decision-making, were categorized under 'being needs'. Finally, the theme 'spiritual needs' categorised conversations/observations when their spiritual/religious needs were met/unmet.

\section{Results}

\section{Participants}

All participants were admitted with chronic confusion and cognitive impairment as a comorbidity, as reported by the charge nurse. Three participants were admitted due to acute 'confusion', another three were admitted with a deterioration in general condition whilst the remaining patients were admitted following an acute chest infection or fever. The average age of the participants was 84.7 years with a 71 to 93 years' age range. Interestingly, the average length of stay of the patients from the first day of fieldwork was 92 days (around 3 months) ranging from 16 days to 177 days (around 6 months). Together with cognitive impairment, a number of patients had communication problems; one patient was blind and another three 
patients had significant hearing difficulties. For these patients, the questions were also asked to the family members who were present during the interview. For one patient, it was not possible to carry out the observation since she deteriorated physically between the time of the interview and the period of observation. In one of the wards, a care worker was assigned to constant observation of three patients with dementia in order to prevent them from leaving the room. His views were also taken regarding the hospital experience of the patients assigned to him. Patient interviews took an average of 15 minutes each.

\section{Biological and physiological needs}

The majority of the patients and their family members interviewed acknowledged that their basic needs such as assistance in washing, dressing, feeding, mobility were occasionally being met:

"We come, so since we are here, we feed her. If we come late, they start feeding her themselves (the ward staff). They do it for us" (relative of Mary)

This was also occasionally observed during DCM such as when staff assisted patients in drinking, feeding, toileting or when changing a wound dressing. However, this was mostly carried out in a rush and as part of the nursing routine. Ward staff were rarely observed asking the patients whether their basic needs were being met whilst patients reported that they were reluctant to ask ward staff for assistance to meet some of these needs:

"Lucy: .... I do not ask them (for tea) every time.

Interviewer: You do not like to ask them every time (for a cup of tea).

Lucy: Yes, I hate it...I like it when they bring it (without me asking)

Interviewer: So, you prefer that they take the initiative

Lucy: Yes, instead of asking

Interviewer: Do they know that you like tea and coffee?

Lucy: They know, because when they bring me I take it.

Interviewer: Would you like some tea?

Lucy: Of course. I am feeling cold.

Interviewer: Would you like some tea now?

Lucy: Of course. A hot cup of tea. I don't want to be pretentious.

Interviewer: I understand. 
Lucy: To feel warm not because I want to be pretentious"

Family members also expressed the lack of support to assist in basic physiological needs such as toileting and their reluctance to ask for help:

"Interviewer 2: Can she find the toilet in here, can she? (asking the relative)

Relative: No but when she was in the other ward, the bed was here and the toilet was close, so she could go with the helper.

Interviewer 1: But here it is not like this, is it too far away?

Relative: Yes, it is a bit far. Next to where they eat.

Interviewer 1: Does she know where the toilet is?

Relative: They do not let her walk (to the toilet) alone, because now she is 'stuck', with the frame she walks but her feet...

Interviewer 1: Is she with a nappy now?

Relative: She used to use the nappy at home... but they were (actually) pull-ups. When you ask her whether she has a nappy on, she used to tell you 'no I have a panty'. But over here, they put a nappy on and she did not realise that she has a nappy.

Interviewer 1: Is she incontinent now?

Relative: She goes to the toilet but they want her do it in the nappy.

Interviewer 1: You mean the nurses?

Relative: The nurses, they tell her, 'Do it, you have the nappy!' But she still does not want to. But how, can the nurse do...I don't...

Interviewer 2: They just need to help her..."

A ward staff also commented on the difficulty to promote continence when other staff do not promote these basic needs:

Ward staff: I was trying to do toilet training with him. You know it is not continuous (care) here. Yesterday evening, I asked (another carer) 'why did you pull up the bed rail (of the patient)? That one goes to the toilet'. He told me, 'Now he passes urine in the nappy and then we change him.'. He told me, 'Should I leave him wandering about?'.

Interviewer 1: So, it very much depends who is caring for him?

Ward staff: That's it. They put the rails up, they leave him in bed, he will 'pee' in bed and then they clean him. They don't let him go to the toilet.

Other physiological needs that at times remained unmet included hydration and nutrition. For example, Martha was observed during DCM to try to grab a bottle of water all morning and looking around to call for attention and no one seemed to notice her until it was pointed out by the researcher. On another occasion, it had to be the relative of another patient to cut the food and feed Lucy since the food tray was left in front of the patient by the ward staff who left 
without even pulling the bed table down. On a separate occasion, after eating his own lunch, a hospital staff scolded the patient who walked towards the lunch tray of another patient and started touching the utensils, seemingly still hungry. A verbalisation of physical/emotional pain was expressed by two patients during DCM but was ignored by staff:

9:43 - PD - Lucy is saying that she is in pain when she passes urine. Ward staff is tending another patient in the room but completely ignored by ward staff

9:55 - PD - Mary is shouting 'ajma' ('ouch, it hurts'). No one seems to notice

\section{Safety needs}

Staff attention to patients' safety was mainly related to preventing them from leaving the ward. Although attention to patient safety seemed to be a collective effort in one ward, in another ward, staff were being specifically assigned to 'guard' the patients. However, how this issue was resolved depended mostly on who was responsible at the time of 'observation':

Ward staff (referring to John - a patient who is able to walk about in the room): I leave him wandering about. Others restrain him.

Interviewer: Do they restrain him?

Ward staff: Yes

Interviewer: Here (on the chair) or in bed?

Ward staff: Mostly in bed they restrain him. I restrained him, in two months, only twice or three times... but when I come back from break he is always restrained (referring to John).

Interviewer: Why?

Ward staff: Because he goes to other patients and he takes all the things they have.

When mapping we observed that the forms of restraint most commonly used consisted of being tied to the chair with sheets or with putting the bed table in a way that obstructed the patient from getting up. On one occasion a patient was also left without any slippers or footwear so as to discourage the patient from walking. Antonio, another patient, also expressed his frustration at not being given the possibility to walk outside of the room although he felt 'he had to obey.'

Interviewer: Do you walk by yourself alone?

Antonio: Yes of course. I (would) like to walk more but you cannot walk here Interviewer: Why?

Antonio: They (the staff) tell you, (that) you cannot walk outside

Interviewer: So, you remain here in the room? 
Antonio: You cannot walk there (in the corridor), it is simply as that.

Interviewer: Okay, and how do you feel about that?

Antonio When I was not here, after lunch I (used to) go for a walk, but you cannot go outside the door.

Interviewer: How do you feel about it?

Antonio: What?

Interviewer: The fact that you cannot go outside?

Antonio: I cannot complain.

Interviewer: You have to obey?

Antonio: Yes, I have to. I don't want to make it difficult so.

The fact that these patients were trapped in their own room was also observed during DCM:

10:00 - PD - John tries to open the door of the room. Ward staff orders John to close the door because he will hurt himself. He tells him that if he wants he can go and watch what is happening through the window

The ward staff who was 'observing' him acknowledged that Antonio was frustrated that he could not go out, but argued that for safety reasons he could not go out of the room with the patient and leave the other patients unattended.

Whilst safety issues were of a particular concern for the staff, there were occasions were the patient's safety was not given its due attention. This was mentioned by patients particularly with regards to the provision of food that was presented too hot and could cause scalds or burns. Both patients and relatives also referred to the fact that the hospital environment was very noisy and crowded (especially in one ward). One relative suggested that patients who are 'loud' should be treated in separate bays.

Relative of Mary: ... I am not referring for my mother, but other patients, they shout, it is not easy at times. And one I would recommend is that if you have a patient who is very loud, talking, shouting...you should not put a quiet person next to her, because at times they get annoyed. If we are five people and she is awake and we are all talking she gets annoyed.

Interviewer: So, putting the loud patients all together?

Relative: Yes, yes, all together. That is my opinion. It is something that can be done. It is my opinion, I am not pointing fingers or so... 


\section{Belonging needs}

One ward staff was observed trying to occasionally engage in conversation with two of the patients under his care:

10:10 - PE - Ward staff asks John to come next to him and engages in a conversation about his past work

10:37 - PE - Ward staff starts a conversation with Antonio about his previous work as a carpenter. Antonio seems to be enjoying the conversation.

However, social contact between patients and other ward staff mostly occurred during the carrying of daily tasks. This was generally rushed, whilst a number of missed opportunities for increased engagement were observed.

11:30 - PD - Ward staff started feeding Sophia who said nothing during feeding time even when the patient tried to speak.

Personal attention and some affection was mainly provided by family members and, on occasions, by other patients. In one particular instance, it was the relative of another patient next to Lucy who engaged with her in a conversation. The succeeding event followed:

11:15 - PD - Lucy is asking to pass urine. Relative (of the patient next to Lucy) reminded her that she has a catheter in situ. The ward staff told this relative that it is useless to remind her as she would forget about it after a few minutes. The relative told her that she is aware about this but the patient keeps on asking because she may be needing to communicate with others. The ward staff left without saying another word.

Participants pleaded for more attention from the ward staff, as at times, they felt ignored:

Martha: But what is killing me, do you know what it is? I ask them to bring me something...they keep walking and do not bring me (what I am asking for).

Interviewer: They ignore you?

Martha: Exactly, exactly, I hate it...I'd rather die...at times the carer becomes angry...maybe one of them...that is what I don't like because otherwise...I ask 'Oh (Holy) Mary' take me away. Because I am fed up...fed up...fed up...I am telling you... that is the only thing that is making me sad...they do not talk to you and keep on walking...I don't know what to say...should it be like that...in a hospital? 
This feeling of being disregarded by ward staff was particularly experienced by patients under constant observation with the responsible ward staff commenting that he also felt left of being left on his own:

Interviewer: Is there anything else you want to tell us about the hospital?

Antonio: No, no. I only see these people here (referring to the ward staff).

Interviewer: But there are a lot of people here around. The doctor just came in now in the room.

Ward staff: You can count them on your fingers.

Interviewer: What?

Ward staff: You can count them on your fingers the persons that come in this room?

Interviewer: Really? Why?

Ward staff: Because I am left here all alone.

\section{Esteem needs}

Both the patients and relatives identified occasions when they were treated with respect. For example, Julie's relative felt that they were being respected when given the opportunity to ask staff about the patient's condition. However, they also argued that sometimes staff themselves were not always fully informed especially when Julie was transferred between wards.

Relative: At times, you know, one thing that hurt me...was when she was transferred to this ward...although they got some information but it was not that complete...you know.

Interviewer: So, there was a lot of missed information.

Relative: I think so. I think so, because when I tell them something...you know...they tell me that they do not know about it or we have to see in the coming days how she is and so on.

Interviewer: So probably something has happened in the other ward and they (the staff in this ward) were not informed.

Relative: Yes, yes...because at one time I knew that her gums were having problems and I was telling them about it. When she came over here and she was transferred (to this ward) I found her mouth was all blood you know, and I asked them. And they told me they did not know about it and I told them listen... ' I have been the last two days telling them'. But once I told them the next day they made an appointment with the dentist...

Mary's relatives felt that there are ward staff who maintained the patient's dignity when 'they feed them nicely, and talk to them nicely'. This was also observed in one particular occasion, when a ward staff asked Angela in a gentle way to change her clothes from her night-dress to 
day clothes, assisted the patient and congratulated her at how well she looked with the day clothes on. Nevertheless, Martha commented that there were a number of occasions when she was not treated with respect:

Interviewer: How do nurses treat you, the nurses in blue?

Martha: I don't recognise them. The persons 'inside' are proud, they really are.

Interviewer: What do you mean by those 'inside'?

Martha: Those that distribute...that work...you know? They shout at me 'Take it'. And I tell her, 'Do not shout at me'

During DCM observations, there were a number of episodes when staff talked to patients in a disrespectful or undignified way such as when they talked to them like they were children or without acknowledging their reality.

10:57 - PD - Mary: tries to get the vest off. Ward staff scolds her 'You cannot undress here. Because Jesus will come for you'

10:15 PD - John sees a lady in the corridor through the window and thinks that she is his wife's mother. Ward staff told John bluntly, 'Your wife's mother is dead, have you forgotten?

Moreover, there were two occasions when staff mocked patients. This also happened during one of the patient interviews:

Interviewer: What do you do in the hospital...for example right now?

Lucy: I observe people.

Interviewer: You observe people. Okay. What do you normally used to do when you were at home?

Lucy: Housework.

Interviewer: Housework at home

(Ward staff comes next to the patient and interrupts the conversation)

Ward staff: She dances Zumba. Tell him!

Lucy: Yes, yes (confused)

Interviewer: Do you like to dance?

Lucy: Yes.

Ward staff: I am just pulling her legs.

The patients' privacy was not always respected such as when a ward staff told the patient not to lock the door of the bathroom, when staff workers talked about the need of a nappy change 
in front of the other patients or when a ward staff was going to change her clothes in front of the other patients:

Relative of Mary: For example, today I just came in and I see them all with the hospital night gown on, I said what happened? I said they are not in prison. (Laughing) I said (to him (the ward staff), 'I will bring her own nightdress'. And he (the ward staff) came to me and said 'I will change it here' and I told him, 'No, I will change it in the bathroom, I will help her change'.

\section{'Being' needs}

Apart from one time when a patient referred to an occasion that she was being useful when asked to fold the towels, most of the patients were perceived and observed to be bored; doing nothing apart from observing what goes around them. Relatives also complained that patients were never engaged in anything except for watching television. The sense of frustration and despair that resulted was particularly evident in this patient:

Interviewer: Georgia... how long have you been in hospital?

Georgia: I think about two mills (months)...I am not feeling well...I am so sad...sad (crying)

Interviewer: Why are you sad?

Georgia: (showing her legs).

Interviewer: Georgia, why are you sad?

Georgia: Oh...I am fed up...it is much better at home (still crying) ...It is so gloomy in here. I am fed up...fed up (crying)

Moreover, patients were rarely empowered and involved in decision making for example in ordering their own food or in deciding what to wear. Martha expressed her dissatisfaction at the food provided and the fact that she is rarely involved in ordering her own food.

Interviewer: Do they (the staff) ask you what you would like to eat?

Martha: No, they bring the food and I tell them to take it away as I have already eaten too much of the same food and I don't eat it...neither in the morning nor in the evening...I am not usually very hungry...I prefer to take a cup of coffee or tea. Interviewer: As far as I know, staff should come and ask you what you would like to eat. Do they every come?

Martha: No, no, never. They just order what they want. 
DCM observations were congruent with the participants' responses. Most of the time under observation, the patients were doing nothing apart from observing the other patients and the staff who occasionally came to perform a task. Engagement in some form of meaningful activity was minimal and mostly discouraged:

11:04 - PD - John is playing with the bed linen and was going to take it off. Ward staff scolded him and threatened him twice that if he does not stop he will tie him up.

\section{Spiritual/religious needs}

Whilst Holy Communion was seen being administered during the periods of observations to some participants, two patients interviewed referred to the need for attending to their spiritual needs particularly hearing mass and attending to confessions which they missed in hospital:

Interviewer: Did you use to hear mass at home?

Georgia: Every day, every day, every day.

Interviewer: Do you go to hear mass here?

Georgia: Not now, no, no never. Not even confessing, they never confess. You know how long (since I received confession) ... How I wish, oh God. I can't.... but at least he gives me you know 'ass'...that?

Interviewer: Absolution?

G: I can't...I can't understand it...

\section{Discussion}

The aim of the study was to categorise the perceived and observed needs of persons with dementia in acute medical wards and to explore whether these needs are being or have been met using Maslow's Hierarchy of Needs as a framework. The findings of this study resonate with a number of other investigations that explored the experiences of older persons and persons with dementia in hospital settings. Cowdell (2009) found that older persons with dementia in acute hospital were more likely to be ignored by ward staff. Similarly, patients with dementia felt excluded, imprisoned, bored (Digby \& Lee, 2017) and perceived by nurses working in geriatric rehabilitation hospital as less 'worthy' of hospital care (Digby, Lee, \& Williams, 2017). Moreover, Hung et al (2017) found that patients with dementia longed for an 
environment that supported social interactions and respect. A systematic review of qualitative studies exploring the views of older people on their experience of acute care including persons with dementia (Bridges, Flatley, \& Meyer, 2010) found that patients felt worthless, fearful and helpless. The feelings expressed by patients and family members in these studies were also identified by the participants in our study especially as unmet 'belongingness' and 'esteem' needs. Our data also found that family members conveyed their concerns that the patients' dignity was not always preserved. This is congruent with other reports in which patients were found to experience humiliation, neglect and loss of dignity (Vries, Drury-Ruddlesden, \& Gual, 2016).

Most of the exploratory studies highlighted above, identified unmet relational and esteem needs. However, the findings of this study also indicate that basic physiological needs such as nutrition, hydration, toileting and maintaining comfort were not always being met. Patients who were unable to communicate these needs were often ignored whilst patients and relatives who could voice their needs to ward staff, were reluctant of doing so. Both patients and relatives seemed to sympathise and occasionally excuse staff due to their heavy workload and time pressures. Moreover, they appeared to be reluctant to complain as they did not want to create any problems to the staff. This sentiment mostly expressed by family members, was also highlighted in other studies (de Vries, Drury-Ruddlesden, \& Gaul, 2016); Scerri, Innes \& Scerri, 2015). The lack of attention given to the physiological needs of patients with dementia by untrained hospital staff, could partly explain the higher risk of negative hospital outcomes including longer hospital stays, delayed discharge, incontinence, delirium and functional decline, when compared to non-cognitive patients (Mukadam \& Sampson, 2011; George, Long, \& Vincent, 2013; Jackson et al., 2017). 
The findings of this study indicated that too much emphasis was perceived and observed to be given by staff on safety needs at the expense of other needs such as 'esteem' and 'being' needs. This was particularly evident for patients who were under constant observation by staff who were assigned to 'guard' patients with dementia deemed at risk of leaving the hospital. The patients' dignity and human rights were not always respected and they seemed to be helpless in these situations. Similarly, Moyle, Borbasi, Wallis, Olorenshaw and Gracia (2010) found, when interviewing acute care staff that the care was mostly focused on risk management at the expense of well-being and dignity. Moreover, Moyle et al. (2010) concluded that staff assigned to constant watch, do not necessary meet the patients' needs. Dewing (2012) also argued that there is currently no empirical evidence base for special observations with older persons with dementia. Whilst the results of this study shed some light on the experience of patients with dementia under constant watch in acute hospital, there is a need for more research that focuses on the views and the perceptions of patients as well as hospital staff assigned to them.

The use of physical restraints was both reported by the participants and observed during Dementia Care Mapping. Although there is clear evidence that their utilisation is associated with numerous adverse outcomes (Rakhmatullina, Taub, \& Jacob, 2013), physical restraints are highly prevalent in institutions both in Malta and abroad. In a cross-sectional study of all public and private nursing homes in Malta, Fenech (2016) indicated that staff working in these homes reported a high observed incidence of physical restraints. Nakanishi, Okumura \& Ogawa (2018), found that among patients with dementia admitted to acute hospitals, the point prevalence of physical restraints was as high as $44.5 \%$. This high prevalence has been attributed to the priority given by hospital staff perceptions around patient safety and risks associated with 'wandering' or falls, at the expense of the patient's esteem needs for dignity and autonomy (Digby, Lee \& Williams, 2017). Gastmans \& Milisen (2006) argued that the decision on whether restraints are adopted, should be taken by staff only when the need for safety outweigh 
the patient's needs for autonomy and dignity and when alternative measures to physical restraints have been exhausted. Although efforts have been made during the past years to reduce restraint use in persons with dementia admitted to hospital (Nakanashi, Okumara, \& Ogawa, 2018), there is still much to be done to encourage hospital staff to consider utilizing alternative interventions. Finally, more evidence is needed in identifying and evaluating the effectiveness of interventions to reduce or prevent the use of physical restraints in general hospital wards (Möhler et al., 2016).

The feeling of boredom and lack of engagement as reported in this study compliments other studies which indicate the need for a ward-based activity service (Prato, Lindley, Boyles, Robinson, \& Abley, 2018). The importance of meaningful activities to foster the psychosocial needs for persons with dementia living in care homes has been examined in the literature (Harmer \& Orrell, 2008). However, little is known about how to meet the need for occupation and engagement in hospital settings. One solution could be to empower and involve the patients in daily ward activities, for example by encouraging and supporting them in filling the menu or in making beds. Other possible interventions could be to involve more family members and other patients without cognitive difficulties as well as the recruitment of activity organisers. A randomised controlled trial (Goldberg et al., 2013) compared a medical and mental health unit (MMHU) with standard care wards in a general hospital. The process evaluation of this trial (Goldberg, Whittamore, Pollock, Harwood \& Gladman, 2014) found that the recruitment and regular engagement of activity coordinators in the MMHU directly contributed to improving the quality care of the patients. Consequently, the role of activity organises/coordinators for patients with dementia in hospitals needs to be further evaluated (Scerri, Innes, Scerri, 2016).

Attending mass and other religious activities in hospital was perceived by patients with dementia, as important both in engaging in a meaningful activity and to meet their spiritual 
needs. Skomakerstuen Ødbehr, Kvigne, Hauge and Danbolt (2015) argued that nursing staff in residential care workers are not trained to recognise the spiritual needs of persons with dementia. The findings of this study indicate that the lack of attention to spiritual care is also present in acute hospitals.

In conclusion, similar to the systematic review of Von Kutzleben et al (2012) that looked at the needs of community-dwelling persons with dementia, patients with dementia in acute hospitals were able to express the whole array of subjective needs as categorized by Maslow (1969) and wanted to be treated as adults irrespective of their cognitive status. However, it is essential for staff to be more aware of all these needs, including 'higher order' needs and identify ways of how to meet them. In this regard, Maslow's Hierarchy of Needs model can be used as a tool to train staff working in acute hospitals, who may be more familiar with this model, rather than Kitwood's model (1997) of psychosocial needs. Moreover, since patients in acute settings may exhibit more physiological needs due to co-morbid conditions, Maslow's model may help ward staff focus on these needs as well as psychosocial needs.

\section{Limitations}

This is a small-scale study conducted in one acute hospital and the findings are therefore not generalizable. Moreover, the sample is focused on patients with cognitive impairment who were able to participate in both interviews and consented to being observed.

\section{Conclusion}

People with dementia have been asked to comment on hospital care on few occasions resulting in a lack of understanding about their hospital stay experiences and their care needs in hospital. This research contributes to the small but growing evidence that favours a design that gives the opportunity for the voice of persons living with dementia to be heard. Consequently, rather than relying mainly on the experiences from hospital staff and family members, more research 
needs to be done on the views of persons living with dementia admitted to acute hospital wards so as to ensure that hospital staff provide care that incorporates their holistic needs.

\section{Acknowledgements}

Special thanks to the persons with dementia who participated in the study.

\section{Authors contributions}

All authors meet at least one of the following criteria and have agreed on the final version:

- Substantial contributions to conception and design, acquisition of data or analysis and interpretation of data;

- Drafting of the article or revising it critically for important intellectual content.

\section{Conflict of interest}

The author(s) declared no potential conflicts of interest with respect to the research, authorship, and/or publication of this article. 


\section{References}

Boaden, A. (2016). Fix dementia care: hospitals. Alzheimer's Society, London. https://www.alzheimers.org.uk/download/downloads/id/2907/fix_dementia_care__hospitals.pdf

Bradford Dementia Group. (2005). Dementia Care Mapping (DCM 8 User's Manual). Bradford: University of Bradford.

Bridges, J., Flatley, M., \& Meyer, J. (2010). Older people's and relatives' experiences in acute care settings: Systematic review and synthesis of qualitative studies. International Journal of Nursing Studies, 47, 89-107

Clissett, P., Porock, D., Harwood, R. H. \& Gladman, J. R. (2013). The challenges of achieving person-centred care in acute hospitals: a qualitative study of people with dementia and their families. International Journal of Nursing Studies, 50(11), 1495-1503.

Cowdell, F. (2010). The care of older people with dementia in acute hospitals. International Journal of Older People Nursing, 5(2), 83-92

de Vries, K., Drury-Ruddlesden, J., \& Gaul, C. (2016). 'And so, I took up residence': The experiences of family members of people with dementia during admission to an acute hospital unit. Dementia, doi: 10.1177/1471301216656097

Dewing, J. (2008). Process consent and research with older persons living with dementia. Research Ethics Review, 4(2), 59-64.

Dewing, J. (2013). Special observation and older persons with dementia/delirium: a disappointing literature review. International Journal of Older People Nursing, 8(1), $19-28$. 
Dewing, J., \& Dijk, S. (2016). What is the current state of care for older people with dementia in general hospitals? A literature review. Dementia, 15(1), 106-124.

Digby, R., Lee, S., \& Williams, A. (2017). The experience of people with dementia and nurses in hospital: an integrative review. Journal of Clinical Nursing, 26(9-10), 1152-1171.

Edvardsson, D., \& Nordvall, K. (2008). Lost in the present but confident of the past: experiences of being in a psycho-geriatric unit as narrated by persons with dementia. Journal of Clinical Nursing, 17(4), 491-498.

Fenech, M. A. (2016). Physical restraint use within long term care settings for older persons in Malta (Doctoral dissertation, University of Nottingham).

Gastmans, C., \& Milisen, K. (2006). Use of physical restraint in nursing homes: clinical-ethical considerations. Journal of Medical Ethics, 32(3), 148-152.

George, J., Long, S., \& Vincent, C. (2013). How can we keep patients with dementia safe in our acute hospitals? A review of challenges and solutions. Journal of the Royal Society of Medicine, 106(9), 355-361.

Goldberg, S. E., Bradshaw, L. E., Kearney, F. C., Russell, C., Whittamore, K. H., Foster, P. E., Mamza, J., Gladman, J. R. F., Jones, R. G., Lewis, S. A., Porock, D. \& Harwood, R. H. (2013) Care in specialist medical and mental health unit compared with standard care for older people with cognitive impairment admitted to general hospital: randomised controlled trial (NIHR TEAM trial). British Medical Journal, 347: f4132. doi: http://dx.doi.org/10.1136/bmj.f4132.

Goldberg, S. E., Whittamore, K. H., Pollock, K., Harwood, R. H. \& Gladman, J. R. F. (2014) Caring for cognitively impaired older patients in the general hospital: a qualitative 
analysis of similarities and differences between a specialist Medical and Mental Health Unit and standard care wards. International Journal of Nursing Studies, 51(10), pp. 1332-1343.

Harmer, B. J., \& Orrell, M. (2008). What is meaningful activity for people with dementia living in care homes? A comparison of the views of older people with dementia, staff and family carers. Aging and Mental health, 12(5), 548-558.

Hung, L., Phinney, A., Chaudhury, H., Rodney, P., Tabamo, J., \& Bohl, D. (2017). “Little things matter!" Exploring the perspectives of patients with dementia about the hospital environment. International Journal of Older People Nursing, 12(3). https://doi.org/10.1111/opn.12153

Jackson, T. A., Gladman, J. R., Harwood, R. H., MacLullich, A. M., Sampson, E. L., Sheehan, B., \& Davis, D. H. (2017). Challenges and opportunities in understanding dementia and delirium in the acute hospital. PLoS medicine, 14(3), https://doi.org/10.1371/journal.pmed.1002247.

Kitwood, T. (1997). Dementia reconsidered: The person comes first, Philadelphia: Open University Press.

Koltko-Rivera, M. E. (2006). Rediscovering the later version of Maslow's hierarchy of needs: Self-transcendence and opportunities for theory, research, and unification. Review of General Psychology, 10(4), 302-317.

Lakey, L. (2009). Counting the cost. Caring for people with dementia on hospital wards. Alzheimer's Society: London, UK.

Lyketsos, C. G., Sheppard, J. E. \& Rabins, P. V. (2000) Dementia in elderly persons in a 
general hospital. American Journal of Psychiatry, 157(5), 704-707.

Maslow, A. H. (1943). A theory of human motivation. Psychological Review, 50, 370-396.

Maslow, A. H. (1969). The farther reaches of human nature. Journal of Transpersonal Psychology, 1(1), 1-9.

Max-Neef, M (1991). Human-Scale Development - conception, application and further reflection, London: Apex Press.

Möhler, R., Nürnberger, C., Abraham, J., Köpke, S., \& Meyer, G. (2016). Interventions for preventing and reducing the use of physical restraints of older people in general hospital settings (Protocol). The Cochrane Library. Doi: 10.1002/14651858.CD012476.

Moyle, W., Borbasi, S., Wallis, M., Olorenshaw, R., \& Gracia, N. (2011). Acute care management of older people with dementia: a qualitative perspective. Journal of Clinical Nursing, 20(3-4), 420-428.

Mukadam, N., \& Sampson, E. L. (2011). A systematic review of the prevalence, associations and outcomes of dementia in older general hospital inpatients. International Psychogeriatrics, 23(3), 344-355.

Nakanishi, M., Okumura, Y., \& Ogawa, A. (2018). Physical restraint to patients with dementia in acute physical care settings: Effect of the financial incentive to acute care hospitals. International Psychogeriatrics, 30(7), 991-1000. doi:http://dx.doi.org.ejournals.um.edu.mt/10.1017/S104161021700240X 
Norman, R. (2006). Observations of the experiences of people with dementia on general hospital wards. Journal of Research in Nursing, 11(5), 453-465.

Nydén, K., Petersson, M., \& Nyström, M. (2003). Unsatisfied basic needs of older patients in emergency care environments-obstacles to an active role in decision making. Journal of Clinical Nursing, 12(2), 268-274.

Prato, L., Lindley, L., Boyles, M., Robinson, L., \& Abley, C. (2018). Empowerment, environment and person-centred care: A qualitative study exploring the hospital experience for adults with cognitive impairment. Dementia. doi: $10.1177 / 1471301218755878$.

Prince, M. J. (2015). World Alzheimer Report 2015: the global impact of dementia: an analysis of prevalence, incidence, cost and trends. Alzheimer's Disease International.

Royal College of Psychiatrists, UK (2011) Report of the National Audit of Dementia Care in General Hospitals. London: Healthcare Quality Improvement Partnership.

Royal College of Psychiatrists, UK (2013) National Audit of Dementia Care in General Hospitals 2012-13: Second round audit report and update. London: Healthcare Quality Improvement Partnership.

Sampson, E. L., Blanchard, M. R., Jones, L., Tookman, A., \& King, M. (2009). Dementia in the acute hospital: prospective cohort study of prevalence and mortality. The British Journal of Psychiatry, 195(1), 61-66

Scerri, A., Innes, A., \& Scerri, C. (2016). Using appreciative inquiry to implement personcentred dementia care in hospital wards. Dementia, doi:1471301216663953. 
Scerri, A., Innes, A., \& Scerri, C. (2015). Discovering what works well: exploring quality dementia care in hospital wards using an appreciative inquiry approach. Journal of Clinical Nursing, 24(13-14), 1916-1925.

Scerri, A. \& Scerri, C. (2012) Dementia in Malta: new prevalence estimates and projected trends. Malta Medical Journal, 24(3), 21-24.

Schölzel-Dorenbos, C. J., Meeuwsen, E. J., \& Olde Rikkert, M. G. (2010). Integrating unmet needs into dementia health-related quality of life research and care: Introduction of the Hierarchy Model of Needs in Dementia. Aging and Mental Health, 14(1), 113119.

Skomakerstuen Ødbehr, L., Kvigne, K., Hauge, S., \& Danbolt, L. J. (2015). A qualitative study of nurses' attitudes towards' and accommodations of patients' expressions of religiosity and faith in dementia care. Journal of Advanced Nursing, 71(2), 359-369.

Timmons, S., O’Shea, E., O’Neill, D., Gallagher, P., de Siún, A., McArdle, D., ... \& Kennelly, S. (2016). Acute hospital dementia care: results from a national audit. BMC Geriatrics, 16(1), 113.

von Kutzleben, M., Schmid, W., Halek, M., Holle, B., \& Bartholomeyczik, S. (2012). Community-dwelling persons with dementia: what do they need? What do they demand? What do they do? A systematic review on the subjective experiences of persons with dementia. Aging \& Mental Health, 16(3), 378-390.

Wahba, M. A., \& Bridwell, L. G. (1976). Maslow reconsidered: A review of research on the need hierarchy theory. Organizational behavior and human performance, 15(2), 212240. 
World Health Organization. (2012). Dementia: a public health priority. World Health Organization.

Zekry, D., Herrmann, F. R., Grandjean, R., Meynet, M. P., Michel, J. P., Gold, G. \& Krause, K. H. (2008) Demented versus non-demented very old inpatients: the same comorbidities but poorer functional and nutritional status. Age and Ageing, 37(1), 8389. 
Table 1. Interview schedule with themes and the questions asked

\begin{tabular}{|c|c|}
\hline Theme & Questions \\
\hline Introductory questions & $\begin{array}{l}\text { What is your name? } \\
\text { Where do you live? } \\
\text { What are you doing now? }\end{array}$ \\
\hline $\begin{array}{c}\text { The hospital environment } \\
\text { Pictures of a hospital bed/hospital } \\
\text { bathroom/ ward labels shown to } \\
\text { patients }\end{array}$ & $\begin{array}{l}\text { What do you think about the environment of this hospital? } \\
\text { Is there anything you would like to include to the hospital environment? } \\
\text { Is there anything you would like to change to the hospital environment? } \\
\text { Have you seen ward labels (such as these) in the ward? Do you find them } \\
\text { helpful? Do you think there are enough? }\end{array}$ \\
\hline $\begin{array}{c}\text { The ward staff } \\
\text { Pictures of a hospital bed/hospital } \\
\text { bathroom/ ward labels shown to } \\
\text { patients }\end{array}$ & $\begin{array}{l}\text { How do nurses/ward staffs interact with you? } \\
\text { How do doctors interact with you? } \\
\text { How do therapists interact with you? } \\
\text { How do the other ward staff (e.g. cleaners) interact with you? }\end{array}$ \\
\hline
\end{tabular}

The care practices Washing/bathing patient

Picture of hospital worker washing/bathing patient

\section{Eating in hospital}

Picture of hospital worker assisting in eating/feeding
Do you need help to bath/wash?

What do you think hospital workers (e.g. nurses) should know when they help you to wash/bath?

Do you like the food provided in the hospital?

Do you need help when eating? Do you find this help when needed? Who helps you?

Is there anything you would like to change in the way lunch is provided in the hospital?

What do you think hospital workers should know when they assist you in feeding?

Do you need help to take your medications? Do you find this help? Who helps you?

Is there anything you would like to change in the way drugs are administered in the hospital?

What do you think hospital workers should know when they are administering your medications?

What do you enjoy doing during the day?

What do you do during the day in hospital?

Would you like to do anything you enjoy doing? What is it?

Are you given the chance in the hospital to do the things you enjoy doing?

Concluding questions
Is there anything you would like to add about your experience in the hospital?

What do you think the ward staff should know to provide you with best care possible? 
Figure 1. Maslow's Hierarchy of Needs (Maslow, 1969)

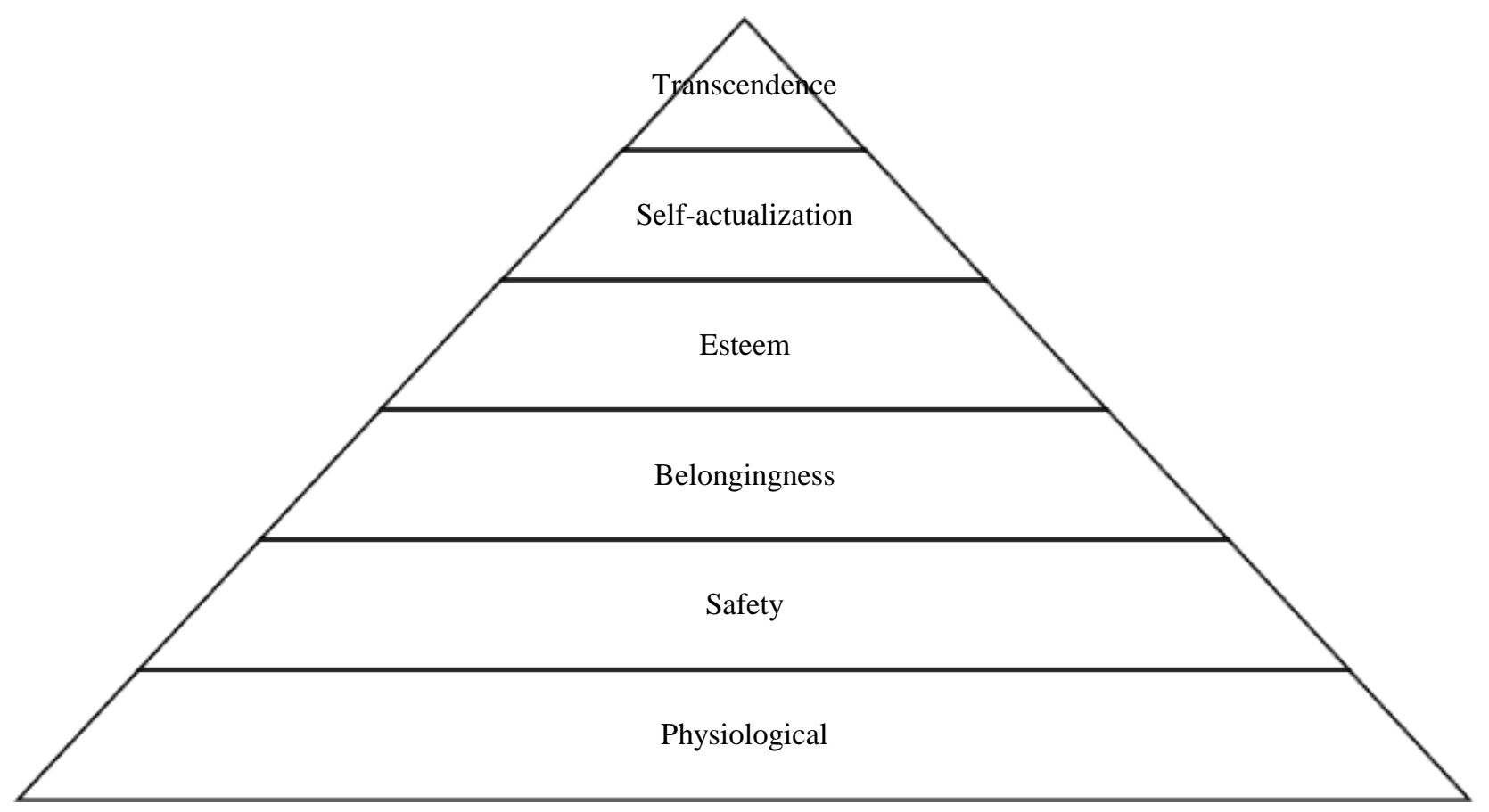

